\title{
The Role of MicroRNA and
} Microbiota in Depression and Anxiety

\author{
Julia M. Rosa1,2,3, Douglas A. Formolo1,2,3, Jiasui Yu1,2,3, Thomas H. Lee ${ }^{1,4}$ and \\ Suk-yu Yau1,2,3*
}

${ }^{1}$ Department of Rehabilitation Sciences, Hong Kong Polytechnic University, Hung Hom, Hong Kong SAR, China, ${ }^{2}$ Mental Health Research Center (MHRC), Hong Kong Polytechnic University, Hung Hom, Hong Kong SAR, China, ${ }^{3}$ Research Institute for Smart Aging (RISA), Hong Kong Polytechnic University, Hung Hom, Hong Kong SAR, China, ${ }^{4}$ Neurocentre Magendie, INSERM U1215, University of Bordeaux, Bordeaux, France

OPEN ACCESS

Edited by:

Alon Shamir,

Mazor Mental Health Center, Israel

Reviewed by:

Therese A. Kosten,

University of Houston, United States Anand Gururajan,

The University of Sydney, Australia

${ }^{*}$ Correspondence:

Suk-yu Yau

sonata.yau@polyu.edu.hk

Specialty section:

This article was submitted to Emotion Regulation and Processing, a section of the journal

Frontiers in Behavioral Neuroscience

Received: 03 December 2021

Accepted: 07 February 2022

Published: 01 March 2022

Citation:

Rosa JM, Formolo DA, Yu J, Lee TH and Yau S-y (2022) The Role of MicroRNA and Microbiota

in Depression and Anxiety.

Front. Behav. Neurosci. 16:828258.

doi: 10.3389/fnbeh.2022.828258
Depression and anxiety are devastating disorders. Understanding the mechanisms that underlie the development of depression and anxiety can provide new hints on novel treatments and preventive strategies. Here, we summarize the latest findings reporting the novel roles of gut microbiota and microRNAs (miRNAs) in the pathophysiology of depression and anxiety. The crosstalk between gut microbiota and the brain has been reported to contribute to these pathologies. It is currently known that some miRNAs can regulate bacterial growth and gene transcription while also modulate the gut microbiota composition, suggesting the importance of miRNAs in gut and brain health. Treatment and prevention strategies for neuropsychiatric diseases, such as physical exercise, diet, and probiotics, can modulate the gut microbiota composition and miRNAs expressions. Nonetheless, there are critical questions to be addressed to understand further the mechanisms involved in the interaction between the gut microbiota and miRNAs in the brain. This review summarizes the recent findings of the potential roles of microbiota and miRNA on the neuropathology of depression and anxiety, and its potential as treatment strategies.

\section{Keywords: microRNA, depression, anxiety, microbiota, psychiatric disorders}

\section{INTRODUCTION}

MicroRNAs (miRNAs) are single-stranded non-coding RNAs, with an average of 22 nucleotides in length, which function as the posttranscriptional regulators of gene expression, primarily through translational repression (Ha and Kim, 2014). Most miRNAs are transcribed from DNA sequences into the primary miRNAs, then processed into the precursor miRNAs, and finally the mature miRNAs (O'Brien et al., 2018). miRNAs are involved in regulating numerous developmental and physiological processes (Ha and Kim, 2014). They are also secreted into the extracellular fluid and serve as the signaling molecules to facilitate cell-to-cell communication (Sohel, 2016). The aberrant expressions of miRNAs are associated with the pathogeneses of cancer (Cui et al., 2019), aging (Kinser and Pincus, 2020), and neuropsychiatric disorders (Xu et al., 2012). Hence, the expressions of miRNAs could be the biomarkers for these diseases, and specifically, miRNAs are suggested as the new pharmacological targets and biomarkers for treating and diagnosing depression and anxiety (Scott et al., 2015; Yuan et al., 2018).

The composition of gut microbiota, on the other hand, is another factor that is associated with psychiatric disorders. Gut microbiota is the microbial flora that inhabits the intestine and is involved in digestion, including bowel movement, food digestion, as well as water and nutrient absorption (Grochowska et al., 2018). Interestingly, changes in the gut microbiota composition may 
eventually contribute to the pathogeneses of neuropsychiatric disorders. Patients with depression, for instance, have altered intestinal microbiota compositions (Amirkhanzadeh Barandouzi et al., 2020). In addition, changes in the microbiota due to antibiotics administration and other conditions can induce depression-like behavior in animals. Chronic unpredictable mild stress promotes anxiety and depression-like behaviors in mice associated with an altered gut microbiota profile, whereas mice colonized with gut microbiota from stressed animals show similar behaviors (Li et al., 2019). Likewise, fecal microbiota transplantation from depressed patients to microbiota-depleted rats can induce depression and anxiety-like behaviors (Kelly et al., 2016).

The miRNA expressions in the brain and the gut microbiota composition are associated with the pathogenesis of depression and anxiety. Critically, miRNAs secreted in the circulation can modulate the microbiota composition, whereas the microbiota composition influences the miRNA expressions in limbic structures that are important for mood regulation. In-depth reviews of the roles of miRNAs and the microbiome in psychiatric disorders such as anxiety and depression can be referred to Meydan et al. (2016), Allen and Dwivedi (2020), Huang and Wu (2021), and Simpson et al. (2021). Here, we review the latest literature by discussing the potential gut microbiota-miRNA crosstalk in modulating depression and anxiety-related disorders, highlighting the relevance of miRNA as the new biomarkers and potential intervention strategies.

\section{THE ROLES OF MICROBIOTA ON DEPRESSION, ANXIETY, AND MicroRNA EXPRESSION}

\section{The Potential Role of Microbiota in Depression}

Depression is characterized by sad or irritable mood accompanied by autonomic and cognitive changes that substantially affect the individual's functionality (American Psychiatric Association, 2013). Depression can be understood from a neurochemical perspective, where a downregulation in the monoaminergic transmission associated with dorsal raphe nucleus (DRN) activity results in poor mood regulation (Coppen, 1967; Cosci and Chouinard, 2019). On the other hand, as it has been more recently proposed, depression is recently proposed as a result from the disintegration of systems and mal-functioning circuits (Manji et al., 2003; Castrén, 2013; Marsden, 2013). In agreement with that, it was recently found that patients with major depressive disorder present lower synaptic density in the dorsolateral prefrontal cortex (PFC), anterior cingulate cortex, and hippocampus (Holmes et al., 2019), all these structures that are involved with emotional reappraisal (Buhle et al., 2014), sadness (Drevets et al., 1997), and cognition (Anacker and Hen, 2017). Increasing structural and synaptic plasticity within these systems have been proposed to be linked to antidepressant actions (Duman et al., 2016).
The relationship between microbiota composition and depression has long been established. Depressed patients have altered microbiota composition compared with healthy controls and decreased microbiota diversity and richness (Kelly et al., 2016; Zheng et al., 2016). Moreover, fecal transplantation from depressed patients to germ-free (GF) rodents induces depressive phenotype that is usually followed by increased anxiety-like behaviors (Kelly et al., 2016; Zheng et al., 2016). However, the mechanisms by which the microbiota affects the brain remain poorly understood. The inflammatory system has been suggested as a possible pathway among the candidates due to its relevance for neuronal development and plasticity (Fung et al., 2017). Indeed, a recent meta-analysis has confirmed that several psychiatric disorders, including depression and anxiety, present reduced gut bacteria responsible for producing the antiinflammatory butyrate along with increased pro-inflammatory generating bacteria (Nikolova et al., 2021). The enteric nervous system also represents a pathway by which alterations in the gut microbiota can directly inform the central nervous system (Bravo et al., 2011). Severing the vagal nerve can block some microbiota effects over central signaling systems (Bravo et al., 2011). Finally, the microbiota composition has been shown to modulate the individuals' response to stress to the same extent to which chronic stress can shape the microbiota composition (Foster and McVey Neufeld, 2013).

In the learned helplessness paradigm, vulnerable rats have altered microbiota composition compared with resilient and control rats, suggesting the microbiome influences stress susceptibility (Zhang et al., 2019). On the other hand, earlylife stress induced by maternal separation induces dysbiosis in the adult offspring displaying depressive phenotype (O'Mahony et al., 2009; de Palma et al., 2015). Likewise, chronic probiotic treatment significantly improves depressive phenotype induced by maternal separation in the adult offspring (Desbonnet et al., 2010). Of note, the beneficial effects of probiotic administration are independent to dysbiosis, such that chronic treatment with a Lactobacillus strain reduces anxiety- and depressionlike behavior in the physiological condition and reduces corticosterone reactivity in response to acute stress (Bravo et al., 2011). Moreover, both acute (ketamine) (Yang et al., 2017) and chronic (fluoxetine) (Zhang et al., 2021) antidepressant treatment are associated with an increased relative abundance of the gut microbiota. Therefore, stress directly influences the microbiota composition, and the microbiota per se can impact stress resilience.

Microbiota composition can directly affect the central nervous systems associated with the glucocorticoid response. Depleted microbiota is associated with increased hippocampal noradrenaline and reduced serotonin levels (de Palma et al., 2015; Hoban et al., 2016), increased neuronal activation in areas associated with stress response, such as the paraventricular nucleus of the hypothalamus (PVN) and bed nucleus of the stria terminalis (BNST) (Wu et al., 2021), and decreased gene expression of glucocorticoid receptors and CHF in the hippocampus and amygdala (Hoban et al., 2016). Likewise, mice with depleted microbiota have increased basal corticosterone levels and HPA reactivity in response to acute stress, which can 
be reversed by microbiota recolonization (Clarke et al., 2013; Wu et al., 2021). Moreover, chronic probiotic treatment reduces the corticosterone reactivity to acute stress and improves depressive phenotype (Bravo et al., 2011; Liang et al., 2015). Noteworthy, probiotic antidepressant effects are associated with improved expression of GABA receptors (Bravo et al., 2011) and restored BDNF, noradrenaline, and serotonin levels in the hippocampus and mPFC (Liang et al., 2015; Sun et al., 2018). Moreover, such probiotic effects are abolished upon vagotomy (Bravo et al., 2011), suggesting the enteric nervous system as a direct communication pathway in the gut-brain axis.

Remarkably, GF rodents tend to present reduced anxietyand depression-like behaviors (Heijtz et al., 2011; Clarke et al., 2013; de Palma et al., 2015; Wu et al., 2021) and are resilient to behavioral impairments induced by maternal separation (de Palma et al., 2015). Such aberrant profile is associated with reduced hippocampal BDNF expression, increased hippocampal and striatal serotonin levels, and plasma tryptophan concentrations (Heijtz et al., 2011; Clarke et al., 2013). Notably, microbiota recolonization in adult life fails to restore some features associated with early life microbiota deficiency, mainly concerning the aberrant hippocampal monoaminergic system activity (Clarke et al., 2013), suggesting a long-lasting effect of early life dysbiosis. Unexpectedly, GF mice that are resilient to maternal separation display depressive phenotypes upon microbiota colonization in adult life (de Palma et al., 2015), suggesting changes of microbiota profile in adulthood can affect stress resilience.

\section{The Potential Roles of Microbiota in Anxiety}

Clinical anxiety is characterized by a broad range of exaggerated and enduring symptoms, such as increased arousal and excessive fear and anxiety-related responses, including autonomic changes, such as increased heart rate and sweating, often in the absence of any real threat or danger (Hoffman and Mathew, 2008). The mechanisms leading to anxiety pathophysiology are not yet fully elucidated, although studies have indicated that anxiety disorders are multifactorial, possibly involving gene and environmental interaction (Hoffman and Mathew, 2008). Similar to depression, ample evidence has shown that the gut microbiota plays a major role in anxiety pathogenesis (Nishino et al., 2013; CrumeyrolleArias et al., 2014; de Palma et al., 2015).

Several early studies have shown anxiolytic-like behaviors in GF rodents, as indicated by increased exploration of unfamiliar areas in the open-field test (OFT) and elevated plus-maze (EPM) test (Heijtz et al., 2011; Crumeyrolle-Arias et al., 2014). A further study has demonstrated the infectious effect of microbiota on anxiety by colonizing GF adult mice with microbiota from specific pathogen-free (SPF) mice (Neufeld et al., 2011). This effect returns to normal as infant rodents enter adulthood (Nishino et al., 2013). Also, offspring subjected to microbiota colonization has shown a significant reduction in spontaneous locomotor activity and anxiety-like behavior (Heijtz et al., 2011).

Anxiety-like behavior can be caused by a dysbiosis of the gut microbiota (Carding et al., 2015; Kc et al., 2020). Rodent studies have demonstrated that intestinal microbiota disruption induced by stress (Bharwani et al., 2017), or high-fat diet (Bruce-Keller et al., 2017), or antibiotics (Park et al., 2021) leads to anxiety-like behavior, which can be restored to normal by probiotic administration, including Escherichia coli (Park et al., 2021) and B. longum (Pinto-Sanchez et al., 2017). These results suggest that anxiety may arise from perturbations in the gut microbiota caused by external conditions. However, the precise mechanisms whereby the dysbiosis of microbiota affects anxiety-like behaviors is still unclear. Recent findings show that disrupted gut microbiota is associated with autoimmune disease and neuroinflammation, as indicated by increased serum levels of the pro-inflammatory cytokines IL-6 and NF- $\kappa$ B (Estes and McAllister, 2015; Schnorr and Bachner, 2016), suggesting that inflammatory response could be potential mediator of gut dysbiosis on inducing anxiety.

The Fusobacterium, such as Lachnospiraceae (Luna and Foster, 2015) and Ruminococcaceae (Tengeler et al., 2020) increases levels of pro-inflammatory cytokine in association with social avoidance. Studies have shown that the microbiota induces release of cytokines and associated pro-inflammatory proteins into the blood (such as TNF- $\alpha$ and interferon- $\gamma$ ), which in turn impair epithelial function and intestinal permeability (Lee and Lee, 2014; Martin-Subero et al., 2016), and activate the intestinal immune cells (de Palma et al., 2017) and primary afferent nerves (Burton and Gebhart, 1995). Anxiety and depression are commonly associated with dysregulation of the HPA axis (van den Bergh et al., 2008), whereas the gut microbiota has been shown essential for regulating the HPA axis activity (Messaoudi et al., 2011; Xu et al., 2020). Dysbiosis-induced release of cytokines may contribute to anxiety via modulation of the HPA axis (Martin-Subero et al., 2016).

Previous studies have found that GF mice are more susceptible to stress-induced hyperactivation of the HPA axis resulting in elevated levels of adrenocorticotropic hormones (ACTH), corticotropin-releasing hormone $(\mathrm{CRH})$, and corticosterone (Huo et al., 2017; Frankiensztajn et al., 2020). However, HPA axis hyperactivity returns to normal after colonization with commensal bacteria (Sudo et al., 2004). Furthermore, rats subjected to maternal separation (an animal model of early life adversity) showed dysbiosis depending on activation of the HPA axis (Cong et al., 2016). However, probiotic (Lactobacillus spp.) treatment normalizes basal cortisol levels and prevents hyperactivation of the HPA axis in offspring from dams with microbiota depletion (Bailey and Coe, 1999).

Lipopolysaccharide (LPS) and peptidoglycan also play critical roles in activating the HPA axis. Several studies have shown that stress not only simulates NF- $\kappa \mathrm{B}$ activation and monocyte migration to the intestine (Jang et al., 2018) but also improves the density of Aspergillus and E. coli in the gut microbiota and increases fecal and serum LPS levels in rodents with anxiety-like behavior (Frankiensztajn et al., 2020). Further investigation suggests that intraperitoneally injection with LPS triggers persistent depression-like behavior in adolescent female mice and anxiety in adult male mice (Yahfoufi et al., 2021). Conversely, pubertal probiotic administration prevents LPSinduced depression/anxiety-like behaviors (Sylvia et al., 2018; Yahfoufi et al., 2021). These results support the hypothesis that LPS from proteobacteria causes an inflammatory response in the 
gastrointestinal tract, which then activates NF- $\mathrm{B}$ signaling and thus the HPA axis, and consequently leads to anxiety (GirardJoyal and Ismail, 2017; Yahfoufi et al., 2021).

Gut-brain communication has been demonstrated to transmit via the vagal nerve (Bercik et al., 2011; Breit et al., 2018; Fülling et al., 2019). Several studies have shown that the gut microbiota may communicate with the brain via intermediate intestinal cells and dendritic cells, conveying endocrine and neurological signals (Westfall et al., 2017; Huh and VeigaFernandes, 2020). In addition, microbial metabolites are potential regulators of neurotransmitter synthesis, for instance shortchain fatty acids, trypsin, 5-hydroxytryptamine, glutamate, and dopamine (Dalile et al., 2019). Thus, there are implications that microbial metabolites facilitate gut-brain communication and behavior regulation. The vagal nerve is chemosensitive and regulates anxiety-like behavior via orexigenic and anorexigenic neuropeptides secreted by enteroendocrine cells (Forsythe et al., 2014). Additionally, the vagal nerve responds to multiple signaling factors released by mast cells and lymphoid cells, including 5-HT and $\mathrm{CRH}$, suggesting the enteric nervous system is also involved in modulating the HPA axis (Gui, 1998).

Anatomical studies have also shown that the sensory neurons of the submucous plexus are in contact with the microbiota and are involved in synaptic neogenesis with the motoneurons of the intestine (Furness et al., 2014), which is associated with the regulation of anxiety-like behaviors (Burokas et al., 2015). Moreover, Campylobacter jejuni increases the expression of c-Fos in vagal afferent brain regions and induces anxiety in mice (Goehler et al., 2005). Additionally, probiotics, such as B. longum, can relieve anxiety through enteric modulation in mice with colitis (Khoshdel et al., 2013).

Probiotics and prebiotics, which can promote the balance of gut microbiota, are of great interest as they also promote anxiety relief (Cryan and O'Mahony, 2011). Decreased anxietylike behavior and plasma corticosterone are observed after prebiotic treatment (fructo-oligosaccharides) in stressed mice (Burokas et al., 2017). Such prebiotic strain also improves the mRNA expression of $\gamma$-aminobutyric acid (GABA) receptors in the hippocampus (Burokas et al., 2017). GABA is one of the major inhibitory neurotransmitters and can be synthesized by intestinal Lactobacilli and Bifidobacteria (Barrett et al., 2012). In addition, dietary probiotics have been shown to support gastrointestinal remodeling by increasing circulating glutathione and reducing inflammatory markers (Aslam et al., 2020).

In summary, the neurobiological study of anxiety and gutCNS connections has revealed potential ways in which microbial disturbances can result in mood and behavior alterations. Although animal experiments have confirmed the use of probiotics to treat anxiety and depression, further mechanistic studies and clinical trials are required to provide scientific evidence on their clinical use.

\section{Effects of Microbiota on Modulating MicroRNA Expression}

Recent studies show that microbiota depleted animals have altered expression of miRNA levels in addition to anxietylike behavior (Hoban et al., 2017), supporting the role of microbiota in influencing the levels of miRNAs. Absence of microbiota in adolescent GF mice results in dysregulation of transcriptome expression in the hippocampus and reduced anxiety-like behavior (Liu et al., 2020). In another study, GF and antibiotic-induced depletion of the microbiota changes the miRNA expression in the amygdala and PFC (Hoban et al., 2017; Table 1). In the amygdala, miR-183-5p and miR-182-5p levels are decreased and subsequently normalized by colonization (Hoban et al., 2017). Both miRNAs are linked with amygdala-dependent stress- and fear-related behaviors (Bocchio-Chiavetto et al., 2013; Griggs et al., 2013). Moreover, miR-219a-2-3p expression in the same brain regions is altered in GF and antibiotic-treated mice (Hoban et al., 2017). Moreover, evidence shows that miR-219a-2$3 \mathrm{p} / \mathrm{miR}-219-3 \mathrm{p}$ are altered in the basolateral amygdala following social defeat stress (Chen et al., 2015).

The microbiome regulates amygdala-dependent fear and anxiety circuitry, and miRNAs are suggested as key mediators (Scott et al., 2015). GF mice have impaired auditory fear conditioning (Scott et al., 2015), which can be related to the apparent incapacity of GF mice to retain the association between conditioned (tone) and unconditioned (shock) stimuli when compared with controls (Hoban et al., 2018). After fear conditioning, miR-34b-5p, miR-34c-5p, and miR-34b-3p are downregulated (Hoban et al., 2018). Interestingly, it is shown that deletion of this miRNA family is related to anxiety resilience in stressed mice and reduced fear memory (Andolina et al., 2016). Together, these data indicate that microbiota and miRNA can be targeted for treating fear- and anxiety-related disorders.

Levels of seven miRNA, including miR-190a-5p, miR-3095-3p, miR-363-5p, miR-421-3p, miR-539-5p, miR-673-3p, miR-758$5 \mathrm{p}$, are changed in the hippocampus when compared to GF mice (Chen et al., 2017). Interestingly, microbiota colonization of GF mice, restore changes of all miRNAs (Chen et al., 2017; Table 1). These miRNAs have reported to be related to neuropsychiatric diseases. Expression of miR-421-3p is changed in the amygdala and serum of rats exposed to acute traumatic stressors, suggesting its role in regulating posttraumatic stress disorder (Balakathiresan et al., 2014). Moreover, maternally separated mice significantly differ in the hippocampal miR-190a5p expression levels (McKibben and Dwivedi, 2021).

In humans, administration of Lactobacillus gasseri CP2305 for 12 weeks improved stress-related behaviors in healthy young students who are with increased basal salivary cortisol and miR144 and miR144* expression levels (Nishida et al., 2017). Moreover, peripheral miR11/144* levels are elevated in medical students during the pre-examination period (Katsuura et al., 2012). Additionally, a decrease in miR144* levels during the post-examination period is correlated with decreased interferongamma (IFN- $\gamma$ ) levels such subjects (Katsuura et al., 2012).

Another aspect that hints at the microbiota relevance for miRNA expression is the commonly observed alterations in patients and animal models with irritable bowel syndrome (IBS). IBS is the most common functional digestive condition, characterized by recurrent abdominal pain and altered bowel movements (Saha, 2014). It is also considered as a complex and heterogeneous disorder with dysfunctional brain-gut axis and gut microbial dysbiosis (Saha, 2014). Not surprisingly, IBS presents high comorbidity with depression and anxiety 
TABLE 1 | Microbiota-induced modulation of miRNA levels in brain regions related to depression/anxiety.

\begin{tabular}{|c|c|c|c|c|c|}
\hline & $\begin{array}{l}\text { Microbiota depletion } \\
\text { strategy }\end{array}$ & Altered miRNAs compared to control & $\begin{array}{l}\text { Behavioral } \\
\text { alterations }\end{array}$ & $\begin{array}{l}\text { Results after microbiota } \\
\text { colonization }\end{array}$ & References \\
\hline Male Swiss Webster & Germ free & $\begin{array}{l}\uparrow \text { miR-3535, miR-187-3p, miR-369-5p } \\
\text { (amygdala) } \\
\downarrow \text { miR-182-5p, miR-183-5p, 219a-2-3p } \\
\text { (amygdala) } \\
\uparrow \text { miR-219a-2-3p (PFC) }\end{array}$ & - & $\begin{array}{l}\text { Restored: miR-182-5p, } \\
\text { miR-182-3p, 219a-2-3p, } \\
\text { miR-122-5p }\end{array}$ & Hoban et al., 2017 \\
\hline Male Sprague Dawley & Cocktail of antibiotics & $\begin{array}{l}\uparrow \text { miR-369-3p (amygdala) } \\
\downarrow \text { miR-206-3p, 219a-2-3p (amygdala) } \\
\downarrow 219 a-2-3 p \text { (PFC) }\end{array}$ & - & - & Hoban et al., 2017 \\
\hline Male C57BL/6J mice & Germ free & $\begin{array}{l}\uparrow \text { miR-184-3p, miR-344c-3p, miR-92b-5p, } \\
\text { miR-342-5p, miR-380-3p, miR-760-3p, } \\
\text { miR-485-3p (amygdala) } \\
\downarrow \text { miR-874-3p, miR-204-5p, miR-211-5p, } \\
\text { miR-1298-5p, miR-448-3p (amygdala) }\end{array}$ & $\downarrow$ Fear memory & Restored: behavior & Hoban et al., 2018 \\
\hline Male Balb/c mice & Germ free & $\begin{array}{l}\uparrow \text { miR-190a-5p, miR-539-5p } \\
\text { (hippocampus) } \\
\downarrow \text { miR-3095-3p, miR-363-5p, miR-421-3p, } \\
\text { miR-673-3p, miR-758-5p (hippocampus) }\end{array}$ & $\downarrow$ Anxiety-like behavior & $\begin{array}{l}\text { No changes in behavior } \\
\text { Restored: All microRNAs }\end{array}$ & Chen et al., 2017 \\
\hline
\end{tabular}

Altered microRNAs in microbiota depletion strategies in brain regions involved with depression and anxiety. $\downarrow$ (Decrease levels) and $\uparrow$ (Increase levels).

disorders (Fond et al., 2014). Recent evidence shows increased miR-24 expression in the enterocytes (epithelial intestinal) in patients and a mouse model of IBS (Liao et al., 2016). By downregulating SERT expression, miR-24 inhibits serotonin reuptake transporter expression and aggravates IBS (Liao et al., 2016). Interestingly, miR-24 inhibitor alleviates intestinal pain and inflammation in IBS mice (Liao et al., 2016). Also, miR-16 and miR-103 are downregulated in the small intestine of IBS patients (Wohlfarth et al., 2017). miR-16 has been reported to mediate depression and anxiety (Song et al., 2015). These findings highlight the importance of new biomarkers involved in IBS and neuropsychiatric disorders, which could be new targets for disease treatment.

\section{THE ROLE OF MicroRNA ON DEPRESSION, ANXIETY, AND MICROBIOTA COMPOSITION}

\section{The Potential Roles of MicroRNAs in Depression}

Stress is one of the most studied etiologic factors for the onset of depression and other psychiatric disorders (Mandelli et al., 2015). Early life traumatic experiences, such as neglect and abuse, increase the risk of developing depression in adult life (Felitti et al., 2019). Prior experiences create a long-lasting change in central and peripheral systems associated with stress regulation, affecting how individuals adapt to future stressors (Ellis et al., 2006). Emerging data demonstrate that miRNAs activity could play a major role in long-lasting changes associated with depression pathogenesis and treatment (Baudry et al., 2010; Issler et al., 2014; Lopez et al., 2014).

Reduced NOTCH1 gene expression, a transmembrane protein necessary for proper development, has been associated with depression and anxiety vulnerability in subjects exposed to traumatic early-life experiences (Steine et al., 2016). NOTCH1 is a target for the miR-34 family. Blood analyses of 32 drugnaïve, first episode depressed patients display the increased levels of miR-34 alongside reduced NOTCH1 mRNA levels, showing a negative association between the levels of miR34 and NOTCH1 mRNA (Sun et al., 2016). miRNA-9 is also suggested to mediate the adverse early life experience with future depression onset and severity, which could be linked with disturbed functional connectivity among prefrontal structures and subcortical limbic systems (He et al., 2021). miRNAs can be secreted into the extracellular fluid, acting as autocrine or paracrine communicators (Bayraktar et al., 2017), suggesting its essential role as potential biomarkers for stress-related neuronal dysfunction.

The relationship among stress, miRNA, and depression has also been validated in several animal models. Maternal deprivation can increase the hippocampal expression of miRNA Let-7a, which negatively correlates with reduced $5-\mathrm{HT}_{4}$ receptors and anhedonia in the adult offspring (Bai et al., 2014). Chronic stress increases depressive phenotypes together with reduced miR-124 (Higuchi et al., 2016), increased miR-182 levels (Li et al., 2016) in the hippocampus, and increased miR-34a in the DRN (Lo Iacono et al., 2020). Chronic corticosterone administration can increase depressive phenotypes and miR124 levels in the mPFC (Roy et al., 2017) and miR-34a levels in the hippocampus (Yi et al., 2020). Chronic stress-induced change in miRNA expressions in the mPFC are associated with altered gene expressions of BDNF, CREB and glutamate receptors, which are involved in synaptic transmission and plasticity (Dwivedi et al., 2015). Moreover, modulating miRNA expression by increasing miR-124 expression in the hippocampus (Higuchi et al., 2016), silencing miR-34 (Lo Iacono et al., 2020), and upregulating miR-135 (Issler et al., 2014) in the DRN, prevents stress-induced depression-like behaviors. Likewise, manipulating miRNA expression itself, such as upregulating hippocampal miR-182 by lentiviral overexpression, can induce 
depression-like behavior and increase the susceptibility to stress (Li et al., 2016). Therefore, accumulated evidence has proved that miRNAs could play a critical role as epigenetic regulators in depression pathogenesis.

MicroRNA expression profile is also sensitive to antidepressant treatment. Microarray analysis of blood from patients after a 12-week antidepressant drug treatment depicted an upregulation of 28 miRNAs and downregulation of two miRNAs when compared to the pre-treatment profile (BocchioChiavetto et al., 2013). Chronic serotonergic antidepressant treatment downregulates serotonin transporter (SERT) and $5-\mathrm{HT}_{1 \mathrm{~A}}$ receptor, which are negatively modulated by the miR135 (Issler et al., 2014). Congruently, depressed patients have reduced peripheral and central miRNA-135 levels, whereas peripheral levels are increased after 3 weeks of cognitivebehavioral therapy (Issler et al., 2014). GRM4 which is targeted by miR-1202, can modulate serotoninergic and glutamatergic synaptic transmission. MiR-1202 is upregulated in the brain and downregulated in the blood of depressed patients, whereas both central and peripheral miRNA levels are normalized in patients taking antidepressant drugs (Lopez et al., 2014).

Selective serotonin reuptake inhibitors (SSRI), which compose most current first-line antidepressant treatments, have a delayed therapeutic onset of 4-8 weeks after treatment started (Trivedi et al., 2006). Chronic serotonergic antidepressant treatment reduces SERT protein expression without affecting its transcriptional level, suggesting translational-regulating mechanisms (Baudry et al., 2010). miR-1202 is reduced in the blood of depressed patients but can be normalized by chronic antidepressant treatment (Lopez et al., 2014). Accordingly, chronic but not acute serotonergic antidepressant treatment in neural progenitor cells upregulates expression levels of miR-1202 (Lopez et al., 2014). Likewise, chronic but not acute SSRI treatment in animals increases expression levels of miR-34a (Lo Iacono et al., 2021) and miR-16 (Baudry et al., 2010) in the DRN, whereas miR-34a is also increased in the hippocampus (Yi et al., 2020). It is suggested that such modulation of miRNA expression upon chronic but not acute serotonergic treatment is a key mediator of the antidepressant effects and one of the mechanisms associated with delayed therapeutic onset.

The relationship between miRNA and the serotonergic system has advanced the understanding of pathogenesis and the treatment of depressive disorders (Babicola et al., 2020). The miR-34 family is reported to be highly relevant to depression. Acute (Andolina et al., 2016) and chronic stress (Lo Iacono et al., 2020) upregulate miRNA-34a levels in the DRN. Knocking out the miR-34 family increases resilience to acute stress-induced anxiety (Andolina et al., 2016), chronic stress-induced depression (Lo Iacono et al., 2020), and switches the coping strategy toward active coping in the forced swim test (Andolina et al., 2018). Acute (Andolina et al., 2016) and chronic (Lo Iacono et al., 2020) stress increase serotonin levels in the mPFC, whereas miR-34 knockout prevents this increase and results in reduced expression of 5- $\mathrm{HT}_{2 \mathrm{C}}$ (Andolina et al., 2016), and increased corticotropinreleasing hormone receptor 1 (CRHR1) (Andolina et al., 2018) in the DRN. Therefore, increased miR-34 could modulate the DRN sensitivity to serotonin and corticotrophin-releasing hormone in response to stress exposure, resulting in increased serotonin input to the mPFC.

miRNAs could also function as crucial mediators of antidepressant treatments and potential therapeutic targets. Chronic corticosterone treatment upregulates hippocampal miR34a levels associated with increased depressive phenotypes (Yi et al., 2020). Chronic treatments with SSRI or miR-34a antagonist counteract corticosterone-induced behavioral deficits in concurrent with restored hippocampal structural plasticity (Yi et al., 2020). Congruently, miRNA-16 infusion into the DRN counteracts chronic stress-induced depression to the same extent as chronic antidepressant treatment with fluoxetine (Baudry et al., 2010). Emerging studies have suggested the potential of manipulating miRNAs expression as a promising antidepressant treatment.

Investigating posttranscriptional mechanisms in depression increases our understanding of how individuals respond and adapt to stress. For example, rats displaying resilience to learned helplessness demonstrate decreased levels of some miRNAs compared to those susceptible to the stressor (Smalheiser et al., 2011). Of note, CREB mRNA, one of the most relevant proteins involved in plasticity and learning (Roy et al., 2013), is a target negatively modulated by many miRNAs (Smalheiser et al., 2011). Furthermore, such a mechanism shed light to unravel one of the most intriguing questions in the pharmacological antidepressant treatment, namely why SSRI acutely increases serotonergic transmission but takes several weeks to have therapeutic effect on symptom relief. As aforementioned, chronic but not acute antidepressant treatment can change the expression of miRNAs associated with key components of the serotonergic system that limit serotonin availability, for instance, SERT and $5-\mathrm{HT}_{2 \mathrm{C}}$ receptors. miRNAs could be a potential therapeutic targets for tackling the etiology of depression with improved therapeutic response.

\section{The Potential Roles of MicroRNAs in Anxiety}

Emerging evidence shows that dysregulation of miRNAs is involved in the stress response (Du et al., 2019), neurodegenerative diseases, and psychiatric disorders $(\mathrm{Ha}$, 2011). miRNAs can be altered by stress, glucocorticoids, and mood stabilizers (Hunsberger et al., 2009), suggesting that miRNAs can also be involved in the pathophysiology of anxiety (Scott et al., 2015).

The majority of clinical studies have analyzed the expression of circulating miRNAs. Patients with generalized anxiety have upregulated peripheral levels of miR-633 and miR-4505, which correlates with the symptom severity (Chen et al., 2016). Panic disorder, on the other hand, has been associated with miR22, miR-138-2, miR-148a, and miR-488 (Muiños-Gimeno et al., 2011). In animals, increased miR-34c levels in the amygdala are associated with acute and chronic stress-induced anxiety (Haramati et al., 2011). Moreover, Fisher 344 rats, a rat strain that displays higher anxiety levels, have increased expression of miR-18a and miR-124 (Uchida et al., 2008). miR-18a is known to inhibit the translation of glucocorticoid receptor (GR), whereas 
miR-124 reduces the GR expression levels (Uchida et al., 2008). Congruently, the expression levels of miR-18a are significantly correlated with the cortisol, corticotropin-releasing factor (CRF), and interleukin-6 (IL-6) plasma levels in humans (Wang et al., 2017a). miR-124-3p, on the other hand, is elevated, while GRs are decreased in the hippocampus of animals submitted to chronic corticosterone administration, an animal model used to mimic chronic stress (Wang et al., 2017b).

Studies also suggest the potential role of miRNAs in the treatment of anxiety. Chronic fluoxetine treatment elicits its antidepressant and anxiolytic effects in mice via increasing miR-16 levels in the serotonergic raphe nuclei, thus reducing the expression of serotonin transporter and increasing the bioavailability of serotonin in the synaptic cleft (Author et al., 2010). Therefore, miRNAs are involved in the pathogenesis of anxiety and depression are found to mediate anxiolytic drug treatments.

\section{Effects of MicroRNA on Microbiota Composition}

The gut microbiota comprises approximately 10-100 trillion microorganisms, including 100-200 bacterial species and about 2-4 million genes (Ursell et al., 2012). Host genetic, diet, and diseases are key factors that can shape the microbiota composition of the host in the mammals (Thursby and Juge, 2017). Recent studies suggest the participation of miRNAs in modulating the gut microbiota composition (Singh et al., 2012). Some miRNAs can regulate bacterial gene transcription, affect bacterial growth and modulate the gut microbiota composition (Singh et al., 2012; Liu et al., 2016). Liu et al. (2016) have identified that miRNAs are abundant in mouse and human fecal samples and present within the extracellular vesicles in the gut lumen. Moreover, depletion of the DICER enzyme (miRNAprocessing enzyme) in mice leads to exacerbated colitis and disturbed microbiota (Liu et al., 2016). On the other hand, when wild-type mice receive fecal miRNA transplantation from healthy mice, it restores fecal microbes and ameliorates colitis (i.e., inflammation of the colon), showing miRNAs influence gut health (Liu et al., 2016).

The gut microbiome has played a pivotal role in mediating the crosstalk between the gut and the brain. The gut-brain axis represents a critical communication system that, when disturbed, can lead to different immune, metabolic, and psychiatric disorders (Dinan and Cryan, 2017). Accumulated research has identified the importance of the gut-brain axis and various microbial-regulated molecular targets in the gut and the brain. Furthermore, it has been recently proposed that miRNAs are crucial signaling molecules to facilitate this bi-directional communication (Moloney et al., 2019).

MicroRNAs can have functional roles similar to hormones, influencing cellular function at a great distance from their original secretory sites (Bayraktar et al., 2017). miRNAs are a constitutive component of murine and human feces derived from host epithelium. They are detectable in feces and are essential for maintaining a normal gut microbiota (Liu et al., 2016). The microbiome regulates behaviors and physiology influenced by
miRNAs (Foster et al., 2017). On the other hand, in germfree (GF) mice, social interaction changes the expressions of miRNA in the amygdala, thus confirming the linkage between a functioning microbiome and sociability, suggesting that miRNA could influence behaviors modulated by the gut microbiome (Stilling et al., 2018). Another brain region influenced by miRNA is the hippocampus. A study has shown that inhibition of miR-124 in the mouse hippocampus improves performance in the Morris Water Maze task and a spontaneous alternation in the closed elevated plus-maze test (Malmevik et al., 2016), demonstrating the critical role of specific miRNAs on regulating behaviors associated with the hippocampus.

The gut microbiota can control gene expression in the brain through a miRNA network and targeted miRNAs (Chen et al., 2017). In silico analysis reveals that miR-294-5p targets the pathway associated with kynurenine metabolism and that genes related to this pathway are differentially expressed in GF mice devoid of all microbiota (Moloney et al., 2017). In the GF mice, it is found that miRNAs in the prefrontal cortex (PFC) and amygdala are sensitive to the presence of a gut microbiome. Upon recolonization, the expressions of some of these miRNAs are normalized. In the amygdala, miR-183-5p and miR-182-5p are decreased in GF mice, whereas expression is subsequently restored upon recolonization (Stilling et al., 2018). These miRNAs have been implicated in the amygdala response to fear and stress (Meerson et al., 2010). For example, miR$183-5 p$ is increased in the circulation of depressed patients after antidepressant treatment (Bocchio-Chiavetto et al., 2013).

To date, there is evidence showing that a microbial product of Bacteroides fragilis lipopolysaccharide can act as a neurotoxin via induction of a series of miRNAs targeting genes that regulate synaptic plasticity, amyloidogenesis, and inflammatory signaling in the brain (Zhao et al., 2021). Also, other metabolites produced by the intestinal microbiota, such as tryptophan, butyrate, acetylcholine, norepinephrine, serotonin, dopamine can influence miRNA activity. They indirectly regulate astrocyte function and blood-brain-barrier integrity and even alter human behavior by disrupting normal neurotransmitter levels (Parker et al., 2020). Taken together, these data suggest that miRNAs are potentially involved in neuronal function and, hence, the pathologies of neurological disorders.

\section{MODULATION OF MicroRNA AND MICROBIOTA FOR THE TREATMENT OF DEPRESSION AND ANXIETY}

Clinical studies have demonstrated the potential involvement of miRNA in modulating the antidepressant effect of probiotics in adults. A 4-week intervention with Lactobacillus gasseri probiotic improves depression symptoms, sleep quality, and bowel habits in adults with chronic stress and changes the miRNAs levels in the blood (Nishida et al., 2017). Moreover, as previously addressed, rodent studies further illustrate the role of microbiota in modulating miRNA expression and mood regulation. Microbiota depletion and recolonization bidirectionally influence the miRNA expression in the limbic 
system (Hoban et al., 2017). Probiotic administration, therefore, could be an effective treatment option.

A recent study examined how postnatal stress influences the affective behaviors of adolescent rodents and their microbiota composition (Karen et al., 2021). Daily maternal separation from postnatal day 5 to 10 induces anxiety- and depressionlike behaviors and reduced gut microbiota diversity and richness (Karen et al., 2021). On the other hand, Lactobacillus paracasei supplementation alleviates anxiety-like behavior and normalizes stress-induced adrenocorticotropic hormone and corticosterone levels in rats (Karen et al., 2021). Comparisons between groups that have undergone maternal separation with and without administration of the probiotic showed that animals that received probiotics had a decrease in miR-132 and an increase in miR-124a levels (Karen et al., 2021). The potential antidepressant effects of probiotics are mediated by miRNA requires further investigation.

Emerging studies suggest that microbiota and microRNA modulation can be adjunct treatment strategies for depression and anxiety (Li et al., 2020). Physical exercise, which is known to have antidepressant and anxiolytic effects, can increase the number of beneficial microbial species (Mailing et al., 2019). A study has showed that $1 \mathrm{~h}$ of wheel running increases the relative abundance of Lachnospiraceae, a family of bacteria known to increase the synthesis of butyrate in the intestine, which is negatively correlated with anxiety-like behavior in adult C57Bl/6J mice (Kang et al., 2014). Butyrate is a short-chain fatty acid related to upregulated brain-derived neurotrophic factor (BDNF) expression in the rodent hippocampus and frontal cortex (Monda et al., 2017). Similar to exercise, butyrate also seems to increase neuroplasticity and has antidepressant effects by boosting serotonin levels (Monda et al., 2017). In addition, it has been reported that regular physical exercise can change the levels of miRNAs (Bye et al., 2013). Aerobic exercise increases the expression of miR-223 while reducing TLR4, MyD88, and NF- $\mathrm{B}$ levels (Qu et al., 2020). Mice exposed to chronic stress have shown increased hippocampal levels of miR-223, which are reduced by 8 weeks of treadmill running (Qu et al., 2020). Moreover, 4 weeks of treadmill running increases the expression levels of miR-129-1$3 \mathrm{p}$, miR-144-5p, and miR-10b-5p in the hippocampus (Fernandes et al., 2018). Eight weeks of antidepressant treatment leads to increased plasma levels of miR-144-5p in patients with depression or anxiety compared to their pre-treatment baseline levels (Wang et al., 2015). Taken together, changes in microbiota and, hence, miRNA expression can contribute to the antidepressant effect of physical exercise.

Diet is another factor that can modulate microbiota and miRNAs (Kang et al., 2014). Obese subjects have increased plasma levels of miR-155 (López et al., 2018), which are also increased in the plasma of depressed patients (Wang et al., 2018). Interestingly, miR-155 is related to the syntheses of pro-inflammatory cytokines, such as TNF- $\alpha$, interleukin-6 (IL6), and monocyte chemoattractant protein-1 (MCP1) (Migita et al., 2017). Mice fed with a high-fat diet decreases miR-137 levels in the cortex (Geekiyanage and Chan, 2011), whereas miR-137 deficiency leads to anxiety-like behavior and altered synaptic transmission and plasticity (Yan et al., 2019). Likewise, postmortem miR-137 levels are downregulated by $25 \%$ in the
PFC of depressed patients with suicidal behavior (Smalheiser et al., 2012). High-fat diet-induces anhedonia-like behavior and decreases circulating leptin levels, which depend on gut microbiota composition (Hassan et al., 2020). Leptin is a hormone involved in regulating energy homeostasis and is associated with reduced depression and anxiety (Lu et al., 2006).

Taken together, these data suggest that the gut-miRNA crosstalk mediates antidepressant and anxiolytic effects and could as well be used as a target for new intervention strategies.

\section{LIMITATIONS AND FUTURE PERSPECTIVES}

Emerging evidence has demonstrated the critical roles of miRNAs and the microbiota on psychiatric disorders, although the investigation of how they interact with each other on disease onset is still in infancy. miRNAs can mediate physiological responses in distal organs which are far apart from their production sites. Epigenetic factors have been proposed to modulate microbiota composition (Liu et al., 2016; Bayraktar et al., 2017). Notably, accumulated evidence from studies using GF mice has indicated that microbiota composition could influence miRNA expression patterns, suggesting direct interaction between gut microbiota and miRNA and their role in depression- and anxiety-like behavior (Chen et al., 2017; Hoban et al., 2017).

This interaction has been also supported by findings reporting the effects of antidepressant and anxiolytic treatments on regulating miRNA expression in the brain (Song et al., 2019) and microbiota composition (Lukić et al., 2019). Future studies identifying detailed mechanism underlying this interaction will help to understand more about the pathophysiology of depression/anxiety and pave the way for new therapeutic targets.

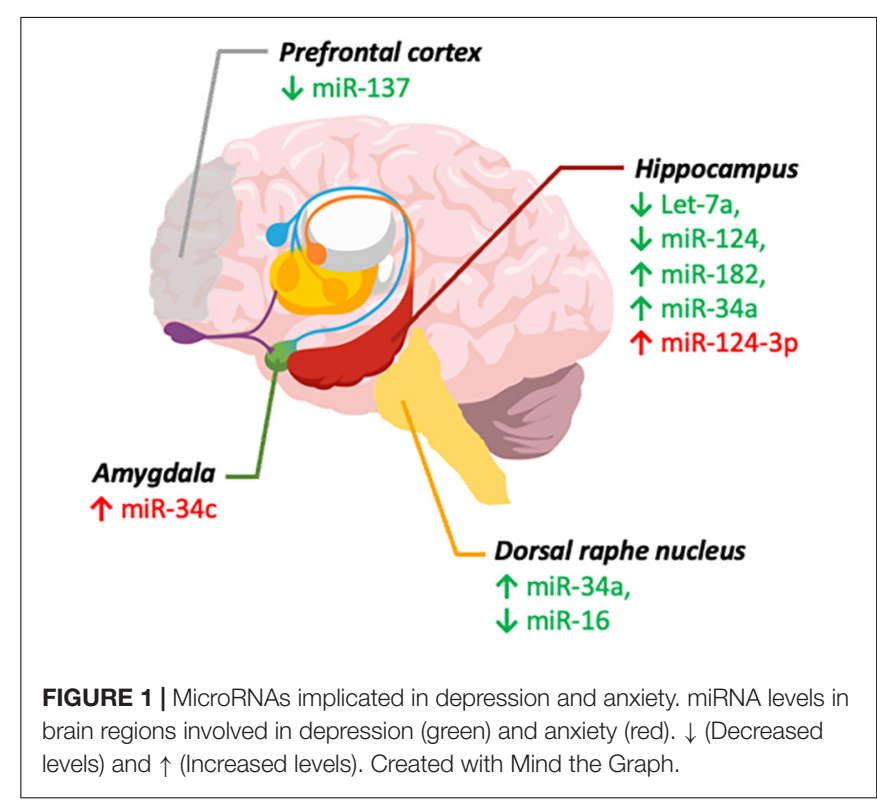


The development of new genetic animal models with knockout, knockdown, or overexpression of specific miRNAs will help to understand the importance of specific miRNAs and their targets on depression and anxiety. However, some miRNAs are present at chromosomes and necessary for embryonic development, making an experimental model of total miRNA depletion unfeasible (Hime et al., 2021). In addition, the multiplicity of targets for individual miRNA has created challenges in understanding the relationship between a single miRNA and a target protein (Liang and Li, 2007). However, up and downregulation of miRNAs in varied brain regions is a feasible alternative (Higuchi et al., 2016), whereas the combination of GF animals with structure-specific miRNA depletion could be alternative experimental approach.

Another alternative to this limitation is the use of nonmammalian models that extend our understanding of the molecular pathologies in human disease (Camkurt et al., 2017). Even though Caenorhabditis elegans and Drosophila melanogaster are evolutionarily distant from human physiology, and most pre-clinical drug tests are performed in rodents, these invertebrate model systems provide alternative approaches to conduct complementary research exploring common epigenetic mechanisms and biochemical processes that linked to neuropsychiatric pathologies (Camkurt et al., 2017).

The clinical investigation of the crosstalk between miRNA and the gut microbiota, and their relationship with mental disorders have specific challenges. One question is to which extent changes of circulating miRNAs represent its changes in central miRNA levels (Jin et al., 2013). Moreover, studies would have to be well controlled because miRNA levels are affected by lifestyle factors, including diet, exercise, drug abuse, and medical conditions, imposing a significant challenge to form homogeneous groups (Jin et al., 2013). As summarized in Figure 1, psychiatric illnesses such as depression and anxiety are linked to altered miRNA expression in specific brain regions associated with mood regulation, such as the mPFC, hippocampus, DRN, and amygdala. Identifying these changes in circulation can help to develop new and more objective diagnostic tools for psychiatric disorders, as well as understanding the roles of aforementioned miRNAs in the relevant brain regions.

Understanding more about the interaction between miRNAs and the gut microbiota can deepen our knowledge

\section{REFERENCES}

Allen, L., and Dwivedi, Y. (2020). MicroRNA mediators of early life stress vulnerability to depression and suicidal behavior. Mol. Psychiatry 25, 308-320. doi: 10.1038/s41380-019-0597-8

American Psychiatric Association (2013). Diagnostic and Statistical Manual of Mental Disorders (DSM-5), 5th Edn. Washington, DC: American Psychiatric Publishing.

Amirkhanzadeh Barandouzi, Z., Starkweather, A. R., Henderson, W. A., Gyamfi, A., and Cong, X. S. (2020). Altered composition of gut microbiota in depression: a systematic review. Front. Psychiatry 11:541. doi: 10.3389/fpsyt.2020.00541

Anacker, C., and Hen, R. (2017). Adult hippocampal neurogenesis and cognitive flexibility-linking memory and mood. Nat. Rev. Neurosci. 18, 335-346. doi: $10.1038 /$ nrn.2017.45 in neuropathologies underlying depression and/or anxiety. The crosstalk between miRNAs and gut microbiota in psychopathologies could provide better understanding of the molecular pathways disrupted in these disorders and eventually pave the way for developing new therapeutic and diagnostic approaches.

\section{CONCLUSION}

Accumulated studies have demonstrated that gut microbiota can influence miRNAs expression in different brain regions related to depression and anxiety, suggesting the potential role of specific miRNAs as an emerging treatment for depression and anxiety. The modulation of microbiota contributes to the mechanisms underlying antidepressant treatments, and comprehending the gut-brain axis leads to a more in-depth understanding of the neuropathology underlying depressive and anxiety disorders. Nonetheless, investigating the mechanisms through which the gut microbiota interacts with miRNAs in the brain is still in its infancy. Although probiotics, physical exercise, and diet intervention could contribute to future treatment strategies, further studies are needed to validate their therapeutic effects on clinical populations with depression, anxiety, and other psychiatric conditions.

\section{AUTHOR CONTRIBUTIONS}

JR wrote and edited the manuscript. DF, JY, and TL contributed to writing the manuscript. S-YY supervised and edited the manuscript. All authors approved the final version of the manuscript and agreed to be accountable for the content of the work.

\section{FUNDING}

This work was supported by funding awarded to S-YY (Hong Kong Research Grant Council, General Research Fund: 15100018, 15104019, and 15104620), Seed funding support from Mental Health Research Center, and Research Institute for Smart Ageing at Hong Kong Polytechnic University.

Andolina, D., di Segni, M., Accoto, A., Lo Iacono, L., Borreca, A., Ielpo, D., et al. (2018). MicroRNA-34 contributes to the stressrelated behavior and affects 5-HT prefrontal/GABA amygdalar system through regulation of corticotropin-releasing factor receptor 1. Mol. Neurobiol. 55, 7401-7412. doi: 10.1007/s12035-0180925-z

Andolina, D., di Segni, M., Bisicchia, E., D’Alessandro, F., Cestari, V., Ventura, A., et al. (2016). Effects of lack of microRNA-34 on the neural circuitry underlying the stress response and anxiety. Neuropharmacology 107, 305-316. doi: 10.1016/ j.neuropharm.2016.03.044

Aslam, H., Green, J., Jacka, F. N., Collier, F., Berk, M., Pasco, J., et al. (2020). Fermented foods, the gut and mental health: a mechanistic overview with implications for depression and anxiety. Nutr. Neurosci. 23, 659-671. doi: 10. 1080/1028415X.2018.1544332 
Author, A., Baudry, A., Mouillet-Richard, S., Schneider, B., Launay, J.-M., and Kellermann, O. (2010). MiR-16 targets the serotonin transporter: a new facet for adaptive responses to antidepressants. Source Sci. New Ser. 329, 1537-1541. doi: 10.1126/science.1129344

Babicola, L., Pietrosanto, M., Ielpo, D., D’Addario, S. L., Cabib, S., Ventura, R., et al. (2020). RISC RNA sequencing in the dorsal raphè reveals microRNAs regulatory activities associated with behavioral and functional adaptations to chronic stress. Brain Res. 1736:146763. doi: 10.1016/j.brainres.2020.146763

Bai, M., Zhu, X. Z., Zhang, Y., Zhang, S., Zhang, L., Xue, L., et al. (2014). Anhedonia was associated with the dysregulation of hippocampal HTR4 and microRNA Let-7a in rats. Physiol. Behav. 129, 135-141. doi: 10.1016/j.physbeh.2014.02.035

Bailey, M. T., and Coe, C. L. (1999). Maternal separation disrupts the integrity of the intestinal microflora in infant rhesus monkeys. Dev. Psychobiol. 35, $146-155$.

Balakathiresan, N. S., Chandran, R., Bhomia, M., Jia, M., Li, H., and Maheshwari, R. K. (2014). Serum and amygdala microRNA signatures of posttraumatic stress: fear correlation and biomarker potential. J. Psychiatr. Res. 57, 65-73. doi: 10.1016/j.jpsychires.2014.05.020

Barrett, E., Ross, R. P., O’Toole, P. W., Fitzgerald, G. F., and Stanton, C. (2012). $\gamma$-Aminobutyric acid production by culturable bacteria from the human intestine. J. Appl. Microbiol. 113, 411-417. doi: 10.1111/j.1365-2672.2012.05344. $\mathrm{x}$

Baudry, A., Mouillet-Richard, S., Schneider, B., Launay, J.-M., and Kellermann, O. (2010). MiR-16 targets the serotonin transporter: a new facet for adaptive responses to antidepressants. Science 329, 1537-1541. doi: 10.1126/science. 1193692

Bayraktar, R., van Roosbroeck, K., and Calin, G. A. (2017). Cell-to-cell communication: microRNAs as hormones. Mol. Oncol. 11, 1673-1686. doi: 10.1002/1878-0261.12144

Bercik, P., Park, A. J., Sinclair, D., Khoshdel, A., Lu, J., Huang, X., et al. (2011). The anxiolytic effect of Bifidobacterium longum NCC3001 involves vagal pathways for gut-brain communication. Neurogastroenterol. Motil. 23, 1132-1139. doi: 10.1111/j.1365-2982.2011.01796.x

Bharwani, A., Mian, M. F., Surette, M. G., Bienenstock, J., and Forsythe, P. (2017). Oral treatment with Lactobacillus rhamnosus attenuates behavioural deficits and immune changes in chronic social stress. BMC Med. 15:7. doi: 10.1186/ s12916-016-0771-7

Bocchio-Chiavetto, L., Maffioletti, E., Bettinsoli, P., Giovannini, C., Bignotti, S., Tardito, D., et al. (2013). Blood microRNA changes in depressed patients during antidepressant treatment. Eur. Neuropsychopharmacol. 23, 602-611. doi: 10. 1016/j.euroneuro.2012.06.013

Bravo, J. A., Forsythe, P., Chew, M. V., Escaravage, E., Savignac, H. M., Dinan, T. G., et al. (2011). Ingestion of Lactobacillus strain regulates emotional behavior and central GABA receptor expression in a mouse via the vagus nerve. Proc. Natl. Acad. Sci. U.S.A. 108, 16050-16055. doi: 10.1073/pnas.1102999108

Breit, S., Kupferberg, A., Rogler, G., and Hasler, G. (2018). Vagus nerve as modulator of the brain-gut axis in psychiatric and inflammatory disorders. Front. Psychiatry 9:44. doi: 10.3389/fpsyt.2018.00044

Bruce-Keller, A. J., Fernandez-Kim, S.-O., Townsend, R. L., Kruger, C., Carmouche, R., Newman, S., et al. (2017). Maternal obese-type gut microbiota differentially impact cognition, anxiety and compulsive behavior in male and female offspring in mice. PLoS One 12:e0175577. doi: 10.1371/journal.pone.017 5577

Buhle, J. T., Silvers, J. A., Wage, T. D., Lopez, R., Onyemekwu, C., Kober, H., et al. (2014). Cognitive reappraisal of emotion: a meta-analysis of human neuroimaging studies. Cereb. Cortex 24, 2981-2990. doi: 10.1093/cercor/bht154

Burokas, A., Arboleya, S., Moloney, R. D., Peterson, V. L., Murphy, K., Clarke, G., et al. (2017). Targeting the microbiota-gut-brain axis: prebiotics have anxiolytic and antidepressant-like effects and reverse the impact of chronic stress in mice. Biol. Psychiatry 82, 472-487. doi: 10.1016/j.biopsych.2016. 12.031

Burokas, A., Moloney, R. D., Dinan, T. G., and Cryan, J. F. (2015). Microbiota regulation of the mammalian gut-brain axis. Adv. Appl. Microbiol. 91, 1-62. doi: 10.1016/bs.aambs.2015.02.001

Burton, M. B., and Gebhart, G. F. (1995). Effects of intracolonic acetic acid on responses to colorectal distension in the rat. Brain Res. 672, 77-82. doi: 10.1016/ 0006-8993(94)01382-r
Bye, A., Røsjø, H., Aspenes, S. T., Condorelli, G., Omland, T., and Wisløff, U. (2013). Circulating microRNAs and aerobic fitness - the HUNT-study. PLoS One 8:e57496. doi: 10.1371/journal.pone.0057496

Camkurt, M. A., Günes, S., Coskun, S., and Findikli, E. (2017). Peripheral signatures of psychiatric disorders: microRNAs. Clin. Psychopharmacol. Neurosci. 15, 313-319. doi: 10.9758/cpn.2017.15.4.313

Carding, S., Verbeke, K., Vipond, D. T., Corfe, B. M., and Owen, L. J. (2015). Dysbiosis of the gut microbiota in disease. Microb. Ecol. Health Dis. 26:26191.

Castrén, E. (2013). Neuronal network plasticity and recovery from depression. JAMA Psychiatry 70, 983-989. doi: 10.1001/jamapsychiatry.2013.1

Chen, J. J., Zeng, B. H., Li, W. W., Zhou, C. J., Fan, S. H., Cheng, K., et al. (2017). Effects of gut microbiota on the microRNA and mRNA expression in the hippocampus of mice. Behav. Brain Res. 322, 34-41. doi: 10.1016/j.bbr.2017. 01.021

Chen, R. J., Kelly, G., Sengupta, A., Heydendael, W., Nicholas, B., Beltrami, S., et al. (2015). MicroRNAs as biomarkers of resilience or vulnerability to stress. Neuroscience 305, 36-48. doi: 10.1016/j.neuroscience.2015.07.045

Chen, S. D., Sun, X. Y., Niu, W., Kong, L. M., He, M. J., Fan, H. M., et al. (2016). Correlation between the level of microRNA expression in peripheral blood mononuclear cells and symptomatology in patients with generalized anxiety disorder. Compr. Psychiatry 69, 216-224. doi: 10.1016/j.comppsych.2016.05.006

Clarke, G., Grenham, S., Scully, P., Fitzgerald, P., Moloney, R. D., Shanahan, F., et al. (2013). The microbiome-gut-brain axis during early life regulates the hippocampal serotonergic system in a sex-dependent manner. Mol. Psychiatry 18, 666-673. doi: 10.1038/mp.2012.77

Cong, X., Xu, W., Romisher, R., Poveda, S., Forte, S., Starkweather, A., et al. (2016). Focus: microbiome: gut microbiome and infant health: brain-gut-microbiota axis and host genetic factors. Yale J. Biol. Med. 89, 299-308.

Coppen, A. (1967). The biochemistry of affective disorders. Br. J. Psychiatry 113, 1237-1264. doi: 10.1007/978-1-4899-6323-9_58

Cosci, F., and Chouinard, G. (2019). "The monoamine hypothesis of depression revisited: could it mechanistically novel antidepressant strategies?, in Neurobiology of Depression: Road to Novel Therapeutics, eds J. Quevedo, A. F. Carvalho, and C. A. Zarate (London: Elsevier Inc). doi: 10.1016/B978-0-12813333-0.00007-X

Crumeyrolle-Arias, M., Jaglin, M., Bruneau, A., Vancassel, S., Cardona, A., Daugé, V., et al. (2014). Absence of the gut microbiota enhances anxiety-like behavior and neuroendocrine response to acute stress in rats. Psychoneuroendocrinology 42, 207-217. doi: 10.1016/j.psyneuen.2014.01.014

Cryan, J. F., and O'Mahony, S. M. (2011). The microbiome-gut-brain axis: from bowel to behavior. Neurogastroenterol. Motil. 23, 187-192. doi: 10.1111/j.13652982.2010.01664.x

Cui, M., Wang, H., Yao, X., Zhang, D., Xie, Y., Cui, R., et al. (2019). Circulating microRNAs in cancer: potential and challenge. Front. Genet. 10:626. doi: 10. 3389/fgene. 2019.00626

Dalile, B., van Oudenhove, L., Vervliet, B., and Verbeke, K. (2019). The role of short-chain fatty acids in microbiota-gut-brain communication. Nat. Rev. Gastroenterol. Hepatol. 16, 461-478. doi: 10.1038/s41575-019-0157-3

de Palma, G., Blennerhassett, P., Lu, J., Deng, Y., Park, A. J., Green, W., et al. (2015). Microbiota and host determinants of behavioural phenotype in maternally separated mice. Nat. Commun. 6:7735. doi: 10.1038/ncomms8735

de Palma, G., Lynch, M. D. J., Lu, J., Dang, V. T., Deng, Y., Jury, J., et al. (2017). Transplantation of fecal microbiota from patients with irritable bowel syndrome alters gut function and behavior in recipient mice. Sci. Transl. Med. 9:eaaf6397. doi: 10.1126/scitranslmed.aaf6397

Desbonnet, L., Garrett, L., Clarke, G., Kiely, B., Cryan, J. F., and Dinan, T. G. (2010). Effects of the probiotic Bifidobacterium infantis in the maternal separation model of depression. Neuroscience 170, 1179-1188. doi: 10.1016/j.neuroscience. 2010.08.005

Dinan, T. G., and Cryan, J. F. (2017). The microbiome-gut-brain axis in health and disease. Gastroenterol. Clin. N. Am. 46, 77-89. doi: 10.1016/j.gtc.2016.09.007

Drevets, W. C., Price, J. L., Simpson, J. R., Todd, R. D., Reich, T., Vannier, M., et al. (1997). Subgenual prefrontal cortex abnormalities in mood disorders. Nature 386, 824-827. doi: 10.1038/386824a0

Du, J., Li, M., Huang, Q., Liu, W., Li, W. Q., Li, Y. J., et al. (2019). The critical role of microRNAs in stress response: therapeutic prospect and limitation. Pharmacol. Res. 142, 294-302. doi: 10.1016/j.phrs.2018.12.007 
Duman, R. S., Aghajanian, G. K., Sanacora, G., and Krystal, J. H. (2016). Synaptic plasticity and depression: new insights from stress and rapid-acting antidepressants. Nat. Med. 22, 238-249. doi: 10.1038/nm.4050

Dwivedi, Y., Roy, B., Lugli, G., Rizavi, H., Zhang, H., and Smalheiser, N. R. (2015). Chronic corticosterone-mediated dysregulation of microRNA network in prefrontal cortex of rats: relevance to depression pathophysiology. Transl. Psychiatry 5:e682. doi: 10.1038/tp.2015.175

Ellis, B. J., Jackson, J. J., and Boyce, W. T. (2006). The stress response systems: universality and adaptive individual differences. Dev. Rev. 26, 175-212. doi: 10.1016/j.dr.2006.02.004

Estes, M. L., and McAllister, A. K. (2015). Immune mediators in the brain and peripheral tissues in autism spectrum disorder. Nat. Rev. Neurosci. 16, 469-486. doi: 10.1038/nrn3978

Felitti, V. J., Anda, R. F., Nordenberg, D., Williamson, D. F., Spitz, A. M., Edwards, V., et al. (2019). Relationship of childhood abuse and household dysfunction to many of the leading causes of death in adults: the adverse childhood experiences (ACE) study. Am. J. Prev. Med. 56, 774-786. doi: 10.1016/j.amepre.2019.04.001

Fernandes, J., Vieira, A. S., Kramer-Soares, J. C., da Silva, E. A., Lee, K. S., Lopes-Cendes, I., et al. (2018). Hippocampal microRNA-mRNA regulatory network is affected by physical exercise. Biochim. Biophys. Acta Gen. Subj. 1862, 1711-1720. doi: 10.1016/j.bbagen.2018.05.004

Fond, G., Loundou, A., Hamdani, N., Boukouaci, W., Dargel, A., Oliveira, J., et al. (2014). Anxiety and depression comorbidities in irritable bowel syndrome (IBS): a systematic review and meta-analysis. Eur. Arch. Psychiatry Clin. Neurosci. 264, 651-660. doi: 10.1007/s00406-014-0502-z

Forsythe, P., Bienenstock, J., and Kunze, W. A. (2014). "Vagal pathways for microbiome-brain-gut axis communication," in Microbial Endocrinology: The Microbiota-Gut-Brain Axis in Health and Disease, eds M. Lyte and J. Cryan (New York, NY: Springer), 115-133. doi: 10.1007/978-1-4939-0897-4_5

Foster, J. A., and McVey Neufeld, K. A. (2013). Gut-brain axis: how the microbiome influences anxiety and depression. Trends Neurosci. 36, 305-312. doi: 10.1016/ j.tins.2013.01.005

Foster, J. A., Rinaman, L., and Cryan, J. F. (2017). Stress \& the gut-brain axis: regulation by the microbiome. Neurobiol. Stress 7, 124-136. doi: 10.1016/j.ynstr. 2017.03.001

Frankiensztajn, L. M., Elliott, E., and Koren, O. (2020). The microbiota and the hypothalamus-pituitary-adrenocortical (HPA) axis, implications for anxiety and stress disorders. Curr. Opin. Neurobiol. 62, 76-82. doi: 10.1016/j.conb.2019. 12.003

Fülling, C., Dinan, T. G., and Cryan, J. F. (2019). Gut microbe to brain signaling: what happens in vagus.... Neuron 101, 998-1002. doi: 10.1016/j.neuron.2019. 02.008

Fung, T. C., Olson, C. A., and Hsiao, E. Y. (2017). Interactions between the microbiota, immune and nervous systems in health and disease. Nat. Neurosci. 20, 145-155. doi: 10.1038/nn.4476

Furness, J. B., Callaghan, B. P., Rivera, L. R., and Cho, H.-J. (2014). “The enteric nervous system and gastrointestinal innervation: integrated local and central control," in Microbial Endocrinology: The Microbiota-Gut-Brain Axis in Health and Disease, eds M. Lyte and J. Cryan (New York, NY: Springer), 39-71. doi: 10.1007/978-1-4939-0897-4_3

Geekiyanage, H., and Chan, C. (2011). Micro RNA-137/181c regulates serine palmitoyltransferase and in turn amyloid $\beta$ novel targets in sporadic Alzheimer's disease. J. Neurosci. 31, 14820-14830. doi: 10.1523/JNEUROSCI.3883-11.2011

Girard-Joyal, O., and Ismail, N. (2017). Effect of LPS treatment on tyrosine hydroxylase expression and Parkinson-like behaviors. Horm. Behav. 89, 1-12. doi: 10.1016/j.yhbeh.2016.12.009

Goehler, L. E., Gaykema, R. P. A., Opitz, N., Reddaway, R., Badr, N., and Lyte, M. (2005). Activation in vagal afferents and central autonomic pathways: early responses to intestinal infection with Campylobacter jejuni. Brain Behav. Immunity 19, 334-344. doi: 10.1016/j.bbi.2004.09.002

Griggs, E. M., Young, E. J., Rumbaugh, G., and Miller, C. A. (2013). MicroRNA-182 regulates amygdala-dependent memory formation. J. Neurosci. 33, 1734-1740. doi: 10.1523/JNEUROSCI.2873-12.2013

Grochowska, M., Wojnar, M., and Radkowski, M. (2018). The gut microbiota in neuropsychiatric disorders. Acta Neurobiol. Exp. 78, 69-81. doi: 10.21307/ane2018-008
Gui, X. (1998). Mast cells: a possible link between psychological stress, enteric infection, food allergy and gut hypersensitivity in the irritable bowel syndrome. J. Gastroenterol. Hepatol. 13, 980-989. doi: 10.1111/j.1440-1746.1998.tb00558.x

Ha, M., and Kim, V. N. (2014). Regulation of microRNA biogenesis. Nat. Rev. Mol. Cell Biol. 15, 509-524. doi: 10.1038/nrm3838

Ha, T.-Y. (2011). MicroRNAs in human diseases: from autoimmune diseases to skin, psychiatric and neurodegenerative diseases. Immune Netw. 11, 227-244. doi: 10.4110/in.2011.11.5.227

Haramati, S., Navon, I., Issler, O., Ezra-Nevo, G., Gil, S., Zwang, R., et al. (2011). MicroRNA as repressors of stress-induced anxiety: the case of amygdalar miR-34. J. Neurosci. 31, 14191-14203. doi: 10.1523/JNEUROSCI.1673-11.2011

Hassan, A. M., Mancano, G., Kashofer, K., Liebisch, G., Farzi, A., Zenz, G., et al. (2020). Anhedonia induced by high-fat diet in mice depends on gut microbiota and leptin. Nutr. Neurosci. 1-14. doi: 10.1080/1028415X.2020.1751508 [Epub ahead of print].

He, C., Bai, Y., Wang, Z., Fan, D., Wang, Q., Liu, X., et al. (2021). Identification of microRNA-9 linking the effects of childhood maltreatment on depression using amygdala connectivity. Neuroimage 224:117428. doi: 10.1016/j.neuroimage. 2020.117428

Heijtz, R. D., Wang, S., Anuar, F., Qian, Y., Bjorkholm, B., Samuelsson, A., et al. (2011). Normal gut microbiota modulates brain development and behavior. Proc. Natl. Acad. Sci. U.S.A. 108, 3047-3052. doi: 10.1073/pnas.1010529108

Higuchi, F., Uchida, S., Yamagata, H., Abe-Higuchi, N., Hobara, T., Hara, K., et al. (2016). Hippocampal microRNA-124 enhances chronic stress resilience in mice. J. Neurosci. 36, 7253-7267. doi: 10.1523/JNEUROSCI.0319-16.2016

Hime, G. R., La Stonehouse, S., and Pang, T. Y. (2021). Alternative models for transgenerational epigenetic inheritance: molecular psychiatry beyond mice and man. World J. Psychiatry 11, 711-735. doi: 10.5498/wjp.v11.i10.711

Hoban, A. E., Moloney, R. D., Golubeva, A. V., McVey Neufeld, K. A., O’Sullivan, O., Patterson, E., et al. (2016). Behavioural and neurochemical consequences of chronic gut microbiota depletion during adulthood in the rat. Neuroscience 339, 463-477. doi: 10.1016/j.neuroscience.2016.10.003

Hoban, A. E., Stilling, R. M., Moloney, G. M., Moloney, R. D., Shanahan, F., Dinan, T. G., et al. (2017). Microbial regulation of microRNA expression in the amygdala and prefrontal cortex. Microbiome 5:102. doi: 10.1186/s40168-0170321-3

Hoban, A. E., Stilling, R. M., Moloney, G., Shanahan, F., Dinan, T. G., Clarke, G., et al. (2018). The microbiome regulates amygdala-dependent fear recall. Mol. Psychiatry 23, 1134-1144. doi: 10.1038/mp.2017.100

Hoffman, E. J., and Mathew, S. J. (2008). Anxiety disorders: a comprehensive review of pharmacotherapies. Mt. Sinai J. Med. 75, 248-262. doi: 10.1002/msj. 20041

Holmes, S. E., Scheinost, D., Finnema, S. J., Naganawa, M., Davis, M. T., DellaGioia, N., et al. (2019). Lower synaptic density is associated with depression severity and network alterations. Nat. Commun. 10:1529. doi: 10.1038/s41467-01909562-7

Huang, F., and Wu, X. (2021). Brain neurotransmitter modulation by gut microbiota in anxiety and depression. Front. Cell Dev. Biol. 9:649103. doi: $10.3389 /$ fcell.2021.649103

Huh, J. R., and Veiga-Fernandes, H. (2020). Neuroimmune circuits in inter-organ communication. Nat. Rev. Immunol. 20, 217-228. doi: 10.1038/s41577-0190247-z

Hunsberger, J. G., Austin, D. R., Chen, G., and Manji, H. K. (2009). MicroRNAs in mental health: from biological underpinnings to potential therapies. Neuromol. Med. 11, 173-182. doi: 10.1007/s12017-009-8070-5

Huo, R., Zeng, B., Zeng, L., Cheng, K., Li, B., Luo, Y., et al. (2017). Microbiota modulate anxiety-like behavior and endocrine abnormalities in hypothalamicpituitary-adrenal axis. Front. Cell. Infect. Microbiol. 7:489. doi: 10.3389/fcimb. 2017.00489

Issler, O., Haramati, S., Paul, E. D., Maeno, H., Navon, I., Zwang, R., et al. (2014). MicroRNA 135 is essential for chronic stress resiliency, antidepressant efficacy, and intact serotonergic activity. Neuron 83, 344-360. doi: 10.1016/j.neuron. 2014.05.042

Jang, H. M., Lee, K. E., and Lee, H. J. (2018). Immobilization stress-induced Escherichia coli causes anxiety by inducing NF- $\mathrm{B}$ activation through gut microbiota disturbance. Sci. Rep. 8:13897. doi: 10.1038/s41598-018-31764-0 
Jin, X. F., Wu, N., Wang, L., and Li, J. (2013). Circulating microRNAs: a novel class of potential biomarkers for diagnosing and prognosing central nervous system diseases. Cell. Mol. Neurobiol. 33, 601-613. doi: 10.1007/s10571-013-9940-9

Kang, S. S., Jeraldo, P. R., Kurti, A., Miller, M. E. B., Cook, M. D., Whitlock, K., et al. (2014). Diet and exercise orthogonally alter the gut microbiome and reveal independent associations with anxiety and cognition. Mol. Neurodegen. 9:36. doi: 10.1186/1750-1326-9-36

Karen, C., Shyu, D. J. H., and Rajan, K. E. (2021). Lactobacillus paracasei supplementation prevents early life stress-induced anxiety and depressive-like behavior in maternal separation model-possible involvement of microbiotagut-brain axis in differential regulation of microRNA124a/132 and glutamate receptors. Front. Neurosci. 15:719933. doi: 10.3389/fnins.2021.719933

Katsuura, S., Kuwano, Y., Yamagishi, N., Kurokawa, K., Kajita, K., Akaike, Y., et al. (2012). MicroRNAs miR-144/144* and miR-16 in peripheral blood are potential biomarkers for naturalistic stress in healthy Japanese medical students. Neurosci. Lett. 516, 79-84. doi: 10.1016/j.neulet.2012.03.062

Kc, D., Sumner, R., and Lippmann, S. (2020). Gut microbiota and health. Postgrad. Med. 132:274.

Kelly, J. R., Borre, Y., O’Brien, C., Patterson, E., el Aidy, S., Deane, J., et al. (2016). Transferring the blues: depression-associated gut microbiota induces neurobehavioural changes in the rat. J. Psychiatr. Res. 82, 109-118. doi: 10.1016/ j.jpsychires.2016.07.019

Khoshdel, A., Verdu, E. F., Kunze, W., McLean, P., Bergonzelli, G., and Huizinga, J. D. (2013). Bifidobacterium longum NCC 3001 inhibits AH neuron excitability. Neurogastroenterol. Motil. 25, e478-e484. doi: 10.1111/nmo.12147

Kinser, H. E., and Pincus, Z. (2020). MicroRNAs as modulators of longevity and the aging process. Hum. Genet. 139, 291-308. doi: 10.1007/s00439-019-02 046-0

Lee, K. N., and Lee, O. Y. (2014). Intestinal microbiota in pathophysiology and management of irritable bowel syndrome. World J. Gastroenterol. 20, 88868897. doi: 10.3748/wjg.v20.i27.8886

Li, M., Chen, W. D., and Wang, Y. D. (2020). The roles of the gut microbiotamiRNA interaction in the host pathophysiology. Mol. Med. 26:101. doi: 10. 1186/s10020-020-00234-7

Li, N., Wang, Q., Wang, Y., Sun, A., Lin, Y., Jin, Y., et al. (2019). Fecal microbiota transplantation from chronic unpredictable mild stress mice donors affects anxiety-like and depression-like behavior in recipient mice via the gut microbiota-inflammation-brain axis. Stress 22, 592-602. doi: 10.1080/ 10253890.2019.1617267

Li, Y., Li, S., Yan, J., Wang, D., Yin, R., Zhao, L., et al. (2016). MiR-182 (microRNA182) suppression in the hippocampus evokes antidepressant-like effects in rats. Prog. Neuro Psychopharmacol. Biol. Psychiatry 65, 96-103. doi: 10.1016/j.pnpbp. 2015.09.004

Liang, H., and Li, W. H. (2007). MicroRNA regulation of human proteinprotein interaction network. RNA 13, 1402-1408. doi: 10.1261/rna.63 4607

Liang, S., Wang, T., Hu, X., Luo, J., Li, W., Wu, X., et al. (2015). Administration of Lactobacillus helveticus NS8 improves behavioral, cognitive, and biochemical aberrations caused by chronic restraint stress. Neuroscience 310, 561-577. doi: 10.1016/j.neuroscience.2015.09.033

Liao, X. J., Mao, W. M., Wang, Q., Yang, G. G., Wu, W. J., and Shao, S. X. (2016). MicroRNA-24 inhibits serotonin reuptake transporter expression and aggravates irritable bowel syndrome. Biochem. Biophys. Res. Commun. 469, 288-293. doi: 10.1016/j.bbrc.2015.11.102

Liu, L., Wang, H., Yu, Y., Zeng, B., Rao, X., Chen, J., et al. (2020). Microbial regulation of a lincRNA-miRNA-mRNA network in the mouse hippocampus. Epigenomics 12, 1377-1383. doi: 10.2217/epi-2019-0307

Liu, S., da Cunha, A. P., Rezende, R. M., Cialic, R., Wei, Z., Bry, L., et al. (2016). The host shapes the gut microbiota via fecal microRNA. Cell Host Microbe 19, 32-43. doi: 10.1016/j.chom.2015.12.005

Lo Iacono, L., Ielpo, D., Accoto, A., di Segni, M., Babicola, L., D’Addario, S. L., et al. (2020). MicroRNA-34a regulates the depression-like behavior in mice by modulating the expression of target genes in the dorsal raphè. Mol. Neurobiol. 57, 823-836. doi: 10.1007/s12035-019-01750-2

Lo Iacono, L., Ielpo, D., Parisi, C., Napoli, G., Accoto, A., di Segni, M., et al. (2021). MicroRNA-34a regulates 5-HT2C expression in dorsal raphe and contributes to the anti-depressant-like effect of fluoxetine. Neuropharmacology 190:108559. doi: 10.1016/j.neuropharm.2021.108559
Lopez, J. P., Lim, R., Cruceanu, C., Crapper, L., Fasano, C., Labonte, B., et al. (2014). MiR-1202 is a primate-specific and brain-enriched microRNA involved in major depression and antidepressant treatment. Nat. Med. 20, 764-768. doi: $10.1038 / \mathrm{nm} .3582$

López, P., Castro, A., Flórez, M., Miranda, K., Aranda, P., Sánchez-González, C., et al. (2018). miR-155 and miR-122 expression of spermatozoa in obese subjects. Front. Genet. 9:175. doi: 10.3389/fgene.2018.00175

Lu, X.-Y., Kim, C. S., Frazer, A., and Zhang, W. (2006). Leptin: a potential novel antidepressant. Proc. Natl. Acad. Sci. U.S.A. 103, 1593-1598. doi: 10.1073/pnas. 0508901103

Lukić, I., Getselter, D., Ziv, O., Oron, O., Reuveni, E., Koren, O., et al. (2019). Antidepressants affect gut microbiota and Ruminococcus flavefaciens is able to abolish their effects on depressive-like behavior. Transl. Psychiatry 9:133. doi: 10.1038/s41398-019-0466-x

Luna, R. A., and Foster, J. A. (2015). Gut brain axis: diet microbiota interactions and implications for modulation of anxiety and depression. Curr. Opin. Biotechnol. 32, 35-41. doi: 10.1016/j.copbio.2014.10.007

Mailing, L. J., Allen, J. M., Buford, T. W., Fields, C. J., and Woods, J. A. (2019). Exercise and the gut microbiome: a review of the evidence, potential mechanisms, and implications for human health. Exerc. Sport Sci. Rev. 47, 75-85. doi: 10.1249/JES.0000000000000183

Malmevik, J., Petri, R., Knauff, P., Brattås, P. L., Åkerblom, M., and Jakobsson, J. (2016). Distinct cognitive effects and underlying transcriptome changes upon inhibition of individual miRNAs in hippocampal neurons. Sci. Rep. 6:19879. doi: 10.1038/srep19879

Mandelli, L., Petrelli, C., and Serretti, A. (2015). The role of specific early trauma in adult depression: a meta-analysis of published literature. Childhood trauma and adult depression. Eur. Psychiatry 30, 665-680. doi: 10.1016/j.eurpsy.2015.04.007

Manji, H. K., Quiroz, J. A., Sporn, J., Payne, J. L., Denicoff, K., Gray, N. A., et al. (2003). Enhancing neuronal plasticity and cellular resilience to develop novel, improved therapeutics for difficult-to-treat depression. Biol. Psychiatry 53, 707-742. doi: 10.1016/S0006-3223(03)00117-3

Marsden, W. N. (2013). Synaptic plasticity in depression: molecular, cellular and functional correlates. Prog. Neuro Psychopharmacol. Biol. Psychiatry 43, 168-184. doi: 10.1016/j.pnpbp.2012.12.012

Martin-Subero, M., Anderson, G., Kanchanatawan, B., Berk, M., and Maes, M. (2016). Comorbidity between depression and inflammatory bowel disease explained by immune-inflammatory, oxidative, and nitrosative stress; tryptophan catabolite; and gut-brain pathways. CNS Spectr. 21, 184-198. doi: $10.1017 /$ S1092852915000449

McKibben, L. A., and Dwivedi, Y. (2021). Early-life stress induces genome-wide sex-dependent miRNA expression and correlation across limbic brain areas in rats. Epigenomics 13, 1031-1056. doi: 10.2217/epi-2021-0037

Meerson, A., Cacheaux, L., Goosens, K. A., Sapolsky, R. M., Soreq, H., and Kaufer, D. (2010). Changes in brain microRNAs contribute to cholinergic stress reactions. J. Mol. Neurosci. 40, 47-55. doi: 10.1007/s12031-009-9252-1

Messaoudi, M., Violle, N., Bisson, J.-F., Desor, D., Javelot, H., and Rougeot, C. (2011). Beneficial psychological effects of a probiotic formulation (Lactobacillus helveticus R0052 and Bifidobacterium longum R0175) in healthy human volunteers. Gut Microbes 2, 256-261. doi: 10.4161/gmic.2.4.16108

Meydan, C., Shenhar-Tsarfaty, S., and Soreq, H. (2016). MicroRNA regulators of anxiety and metabolic disorders. Trends Mol. Med. 22, 798-812. doi: 10.1016/j. molmed.2016.07.001

Migita, K., Iwanaga, N., Izumi, Y., Kawahara, C., Kumagai, K., Nakamura, T., et al. (2017). TNF- $\alpha$-induced miR-155 regulates IL-6 signaling in rheumatoid synovial fibroblasts. BMC Res. Notes 10:403. doi: 10.1186/s13104-017-2715-5

Moloney, G. M., Dinan, T. G., Clarke, G., and Cryan, J. F. (2019). Microbial regulation of microRNA expression in the brain-gut axis. Curr. Opin. Pharmacol. 48, 120-126. doi: 10.1016/j.coph.2019.08.005

Moloney, G. M., O’Leary, O. F., Salvo-Romero, E., Desbonnet, L., Shanahan, F., Dinan, T. G., et al. (2017). Microbial regulation of hippocampal miRNA expression: implications for transcription of kynurenine pathway enzymes. Behav. Brain Res. 334, 50-54. doi: 10.1016/j.bbr.2017.07.026

Monda, V., Villano, I., Messina, A., Valenzano, A., Esposito, T., Moscatelli, F., et al. (2017). Exercise modifies the gut microbiota with positive health effects. Oxid. Med. Cell. Longev. 2017:3831972 . doi: 10.1155/2017/3831972

Muiños-Gimeno, M., Espinosa-Parrilla, Y., Guidi, M., Kagerbauer, B., Sipilä, T., Maron, E., et al. (2011). Human microRNAs miR-22, miR-138-2, miR-148a, 
and miR-488 are associated with panic disorder and regulate several anxiety candidate genes and related pathways. Biol. Psychiatry 69, 526-533. doi: 10. 1016/j.biopsych.2010.10.010

Neufeld, K.-A. M., Kang, N., Bienenstock, J., and Foster, J. A. (2011). Effects of intestinal microbiota on anxiety-like behavior. Commun. Integr. Biol. 4, 492-494. doi: 10.4161/cib.15702

Nikolova, V. L., Smith, M. R. B., Hall, L. J., Cleare, A. J., Stone, J. M., and Young, A. H. (2021). Perturbations in gut microbiota composition in psychiatric disorders. JAMA Psychiatry 78, 1343-1354. doi: 10.1001/jamapsychiatry.2021. 2573

Nishida, K., Sawada, D., Kuwano, Y., Tanaka, H., Sugawara, T., Aoki, Y., et al. (2017). Daily administration of paraprobiotic Lactobacillus gasseri CP2305 ameliorates chronic stress-associated symptoms in Japanese medical students. J. Funct. Foods 36, 112-121. doi: 10.1016/j.jff.2017.06.031

Nishino, R., Mikami, K., Takahashi, H., Tomonaga, S., Furuse, M., Hiramoto, T., et al. (2013). Commensal microbiota modulate murine behaviors in a strictly contamination-free environment confirmed by culture-based methods. Neurogastroenterol. Motil. 25, 521-528. doi: 10.1111/nmo.12110

O'Brien, J., Hayder, H., Zayed, Y., and Peng, C. (2018). Overview of microRNA biogenesis, mechanisms of actions, and circulation. Front. Endocrinol. 9:402. doi: $10.3389 /$ fendo. 2018.00402

O’Mahony, S. M., Marchesi, J. R., Scully, P., Codling, C., Ceolho, A.-M., Quigley, E. M. M., et al. (2009). Early life stress alters behavior, immunity, and microbiota in rats: implications for irritable bowel syndrome and psychiatric illnesses. Biol. Psychiatry 65, 263-267. doi: 10.1016/j.biopsych.2008.06.026

Park, K., Park, S., Nagappan, A., Ray, N., Kim, J., Yoon, S., et al. (2021). Probiotic Escherichia coli ameliorates antibiotic-associated anxiety responses in mice. Nutrients 13:811. doi: 10.3390/nu13030811

Parker, A., Fonseca, S., and Carding, S. R. (2020). Gut microbes and metabolites as modulators of blood-brain barrier integrity and brain health. Gut Microbes 11, 135-157. doi: 10.1080/19490976.2019.1638722

Pinto-Sanchez, M. I., Hall, G. B., Ghajar, K., Nardelli, A., Bolino, C., Lau, J. T., et al. (2017). Probiotic Bifidobacterium longum NCC3001 reduces depression scores and alters brain activity: a pilot study in patients with irritable bowel syndrome. Gastroenterology 153, 448-459.e8. doi: 10.1053/j.gastro.2017.05.003

Qu, H., Liu, R., Chen, J., Zheng, L., and Chen, R. (2020). Aerobic exercise inhibits CUMS-depressed mice hippocampal inflammatory response via activating hippocampal miR-223/TLR4/MyD88-NF-кB pathway. Int. J. Environ. Res. Public Health 17:2676. doi: 10.3390/ijerph17082676

Roy, A., Jana, M., Corbett, G. T., Ramaswamy, S., Kordower, J. H., Gonzalez, F. J., et al. (2013). Regulation of cyclic AMP response element binding and hippocampal plasticity-related genes by peroxisome proliferator-activated receptor $\alpha$. Cell Rep. 4, 724-737. doi: 10.1016/j.celrep.2013.07.028

Roy, B., Dunbar, M., Shelton, R. C., and Dwivedi, Y. (2017). Identification of microRNA-124-3p as a putative epigenetic signature of major depressive disorder. Neuropsychopharmacology 42, 864-875. doi: 10.1038/npp.2016.175

Saha, L. (2014). Irritable bowel syndrome: pathogenesis, diagnosis, treatment, and evidence-based medicine. World J. Gastroenterol. 20, 6759-6773. doi: 10.3748/ wjg.v20.i22.6759

Schnorr, S. L., and Bachner, H. A. (2016). Focus: microbiome: integrative therapies in anxiety treatment with special emphasis on the gut microbiome. Yale J. Biol. Med. 89, 397-422.

Scott, K. A., Hoban, A. E., Clarke, G., Moloney, G. M., Dinan, T. G., and Cryan, J. F. (2015). Thinking small: towards microRNA-based therapeutics for anxiety disorders. Expert Opin. Investig. Drugs 24, 529-542. doi: 10.1517/13543784. 2014.997873

Simpson, C. A., Diaz-Arteche, C., Eliby, D., Schwartz, O. S., Simmons, J. G., and Cowan, C. S. M. (2021). The gut microbiota in anxiety and depression - a systematic review. Clin. Psychol. Rev. 83:101943. doi: 10.1016/j.cpr.2020.101943

Singh, N., Shirdel, E. A., Waldron, L., Zhang, R.-H., Jurisica, I., and Comelli, E. M. (2012). The murine caecal microRNA signature depends on the presence of the endogenous microbiota. Int. J. Biol. Sci. 8, 171-186. doi: 10.7150/ijbs.8.171

Smalheiser, N. R., Lugli, G., Rizavi, H. S., Torvik, V. I., Turecki, G., and Dwivedi, Y. (2012). MicroRNA expression is down-regulated and reorganized in prefrontal cortex of depressed suicide subjects. PLoS One 7:e33201. doi: 10.1371/journal. pone.0033201

Smalheiser, N. R., Lugli, G., Rizavi, H. S., Zhang, H., Torvik, V. I., Pandey, G. N., et al. (2011). MicroRNA expression in rat brain exposed to repeated inescapable shock: differential alterations in learned helplessness vs. nonlearned helplessness. Int. J. Neuropsychopharmacol. 14, 1315-1325. doi: 10. $1017 /$ S1461145710001628

Sohel, M. H. (2016). Extracellular/circulating microRNAs: release mechanisms, functions and challenges. Achiev. Life Sci. 10, 175-186. doi: 10.1016/j.als.2016. 11.007

Song, M. F., Dong, J. Z., Wang, Y. W., He, J., Ju, X., Zhang, L., et al. (2015). CSF miR-16 is decreased in major depression patients and its neutralization in rats induces depression-like behaviors via a serotonin transmitter system. J. Affect. Disord. 178, 25-31. doi: 10.1016/j.jad.2015.02.022

Song, W., Shen, Y., Zhang, Y., Peng, S., Zhang, R., Ning, A., et al. (2019). Expression alteration of microRNAs in Nucleus Accumbens is associated with chronic stress and antidepressant treatment in rats. BMC Med. Inf. Decis. Mak. 19:271. doi: 10.1186/s12911-019-0964-z

Steine, I. M., Zayats, T., Stansberg, C., Pallesen, S., Mrdalj, J., Havik, B., et al. (2016). Implication of NOTCH1 gene in susceptibility to anxiety and depression among sexual abuse victims. Transl. Psychiatry 6:e977. doi: 10.1038/tp.2016.248

Stilling, R. M., Moloney, G. M., Ryan, F. J., Hoban, A. E., Fs Bastiaanssen, T., Shanahan, F., et al. (2018). Social interaction-induced activation of RNA splicing in the amygdala of microbiome-deficient mice. eLife 7:e33070. doi: 10.7554/eLife.33070.001

Sudo, N., Chida, Y., Aiba, Y., Sonoda, J., Oyama, N., Yu, X., et al. (2004). Postnatal microbial colonization programs the hypothalamic-pituitary-adrenal system for stress response in mice. J. Physiol. 558, 263-275. doi: 10.1113/jphysiol.2004. 063388

Sun, J., Wang, F., Hu, X., Yang, C., Xu, H., Yao, Y., et al. (2018). Clostridium butyricum attenuates chronic unpredictable mild stress-induced depressive-like behavior in mice via the gut-brain axis. J. Agric. Food Chem. 66, 8415-8421. doi: 10.1021/acs.jafc.8b02462

Sun, N., Lei, L., Wang, Y., Yang, C., Liu, Z., Li, X., et al. (2016). Preliminary comparison of plasma notch-associated microRNA-34b and -34c levels in drug naive, first episode depressed patients and healthy controls. J. Affect. Disord. 194, 109-114. doi: 10.1016/j.jad.2016.01.017

Sylvia, K. E., Deyoe, J. E., and Demas, G. E. (2018). Early-life sickness may predispose Siberian hamsters to behavioral changes following alterations of the gut microbiome in adulthood. Brain Behav. Immunity 73, 571-583. doi: 10.1016/j.bbi.2018.07.001

Tengeler, A. C., Dam, S. A., Wiesmann, M., Naaijen, J., van Bodegom, M., Belzer, C., et al. (2020). Gut microbiota from persons with attention-deficit/hyperactivity disorder affects the brain in mice. Microbiome 8:44. doi: 10.1186/s40168-02000816-x

Thursby, E., and Juge, N. (2017). Introduction to the human gut microbiota. Biochem. J. 474, 1823-1836. doi: 10.1042/BCJ20160510

Trivedi, M. H., Rush, A. J., Wisniewski, S. R., Nierenberg, A. A., Warden, D., Ritz, L., et al. (2006). Evaluation of outcomes with citalopram for depression using measurement-based care in STAR*D: implications for clinical practice. Am. J. Psychiatry 163, 28-40. doi: 10.1176/appi.ajp.163.1.28

Uchida, S., Nishida, A., Hara, K., Kamemoto, T., Suetsugi, M., Fujimoto, M., et al. (2008). Characterization of the vulnerability to repeated stress in Fischer 344 rats: possible involvement of microRNA-mediated down-regulation of the glucocorticoid receptor. Eur. J. Neurosci. 27, 2250-2261. doi: 10.1111/j.14609568.2008.06218.x

Ursell, L. K., Metcalf, J. L., Parfrey, L. W., and Knight, R. (2012). Defining the human microbiome. Nutr. Rev. 70(Suppl. 1), S38-S44. doi: 10.1111/j.17534887.2012.00493.x

van den Bergh, B. R. H., van Calster, B., Smits, T., van Huffel, S., and Lagae, L. (2008). Antenatal maternal anxiety is related to HPA-axis dysregulation and self-reported depressive symptoms in adolescence: a prospective study on the fetal origins of depressed mood. Neuropsychopharmacology 33, 536-545. doi: 10.1038/sj.npp.1301450

Wang, S. S., Li, Y. Q., Liang, Y. Z., Dong, J., He, Y., Zhang, L., et al. (2017a). Expression of miR-18a and miR-34c in circulating monocytes associated with vulnerability to type 2 diabetes mellitus and insulin resistance. J. Cell. Mol. Med. 21, 3372-3380. doi: 10.1111/jcmm.13240

Wang, S. S., Mu, R. H., Li, C. F., Dong, S. Q., Geng, D., Liu, Q., et al. (2017b). microRNA-124 targets glucocorticoid receptor and is involved in depressionlike behaviors. Prog. Neuro Psychopharmacol. Biol. Psychiatry 79, 417-425. doi: 10.1016/j.pnpbp.2017.07.024 
Wang, X., Sundquist, K., Hedelius, A., Palmér, K., Memon, A. A., and Sundquist, J. (2015). Circulating microRNA-144-5p is associated with depressive disorders. Clin. Epigenet. 7:69. doi: 10.1186/s13148-015-0099-8

Wang, X., Wang, B., Zhao, J., Liu, C., Qu, X., and Li, Y. (2018). MiR-155 is involved in major depression disorder and antidepressant treatment via targeting SIRT1. Biosci. Rep. 38:BSR20181139. doi: 10.1042/BSR20181139

Westfall, S., Lomis, N., Kahouli, I., Dia, S. Y., Singh, S. P., and Prakash, S. (2017). Microbiome, probiotics and neurodegenerative diseases: deciphering the gut brain axis. Cell. Mol. Life Sci. 74, 3769-3787. doi: 10.1007/s00018-017-2550-9

Wohlfarth, C., Schmitteckert, S., Härtle, J. D., Houghton, L. A., Dweep, H., Fortea, M., et al. (2017). MiR-16 and miR-103 impact 5-HT4 receptor signalling and correlate with symptom profile in irritable bowel syndrome. Sci. Rep. 7:14680. doi: 10.1038/s41598-017-13982-0

Wu, W.-L., Adame, M. D., Liou, C.-W., Barlow, J. T., Lai, T.-T., Sharon, G., et al. (2021). Microbiota regulate social behaviour via stress response neurons in the brain. Nature 595, 409-414. doi: 10.1038/s41586-021-03669-y

$\mathrm{Xu}$, B., Hsu, P. K., Karayiorgou, M., and Gogos, J. A. (2012). MicroRNA dysregulation in neuropsychiatric disorders and cognitive dysfunction. Neurobiol. Dis. 46, 291-301. doi: 10.1016/j.nbd.2012.02.016

Xu, C., Lee, S. K., Zhang, D., and Frenette, P. S. (2020). The gut microbiome regulates psychological-stress-induced inflammation. Immunity 53, 417428.e4. doi: 10.1016/j.immuni.2020.06.025

Yahfoufi, N., Ah-Yen, E. G., Chandrasegaram, R., Aly, S., Murrack, M., Kadamani, A. K., et al. (2021). Adolescent use of potential novel probiotic Rouxiella badensis subsp. acadiensis (Canan SV-53) mitigates pubertal LPSInduced behavioral changes in adulthood in a sex-specific manner by modulating 5HT1A receptors expression in specific brain areas. Compr. Psychoneuroendocrinol. 7:100063.

Yan, H. L., Sun, X. W., Wang, Z. M., Liu, P. P., Mi, T. W., Liu, C., et al. (2019). MiR-137 deficiency causes anxiety-like behaviors in mice. Front. Mol. Neurosci. 12:260. doi: 10.3389/fnmol.2019.00260

Yang, C., Qu, Y., Fujita, Y., Ren, Q., Ma, M., Dong, C., et al. (2017). Possible role of the gut microbiota-brain axis in the antidepressant effects of (R)-ketamine in a social defeat stress model. Transl. Psychiatry 7:1294. doi: 10.1038/s41398-0170031-4

Yi, L. T., Zhu, J. X., Dong, S. Q., Li, C. F., Zhang, Q. P., Cheng, J., et al. (2020). miR-34a induces spine damages via inhibiting synaptotagmin-1 in depression. Neurobiol. Stress 13:100243. doi: 10.1016/j.ynstr.2020.100243
Yuan, H., Mischoulon, D., Fava, M., and Otto, M. W. (2018). Circulating microRNAs as biomarkers for depression: many candidates, few finalists. J. Affect. Disord. 233, 68-78. doi: 10.1016/j.jad.2017. 06.058

Zhang, K., Fujita, Y., Chang, L., Qu, Y., Pu, Y., Wang, S., et al. (2019). Abnormal composition of gut microbiota is associated with resilience versus susceptibility to inescapable electric stress. Transl. Psychiatry 9:231. doi: 10.1038/s41398-0190571-x

Zhang, W., Qu, W., Wang, H., and Yan, H. (2021). Antidepressants fluoxetine and amitriptyline induce alterations in intestinal microbiota and gut microbiome function in rats exposed to chronic unpredictable mild stress. Transl. Psychiatry 11:131. doi: 10.1038/s41398-02101254-5

Zhao, L., Ye, Y., Gu, L., Jian, Z., Stary, C. M., and Xiong, X. (2021). Extracellular vesicle-derived miRNA as a novel regulatory system for bidirectional communication in gut-brain-microbiota axis. J. Transl. Med. 19:202. doi: 10.1186/s12967-021-02861-y

Zheng, P., Zeng, B., Zhou, C., Liu, M., Fang, Z., Xu, X., et al. (2016). Gut microbiome remodeling induces depressive-like behaviors through a pathway mediated by the host's metabolism. Mol. Psychiatry 21, 786-796. doi: 10.1038/ mp.2016.44

Conflict of Interest: The authors declare that the research was conducted in the absence of any commercial or financial relationships that could be construed as a potential conflict of interest.

Publisher's Note: All claims expressed in this article are solely those of the authors and do not necessarily represent those of their affiliated organizations, or those of the publisher, the editors and the reviewers. Any product that may be evaluated in this article, or claim that may be made by its manufacturer, is not guaranteed or endorsed by the publisher.

Copyright (C) 2022 Rosa, Formolo, Yu, Lee and Yau. This is an open-access article distributed under the terms of the Creative Commons Attribution License (CC BY). The use, distribution or reproduction in other forums is permitted, provided the original author(s) and the copyright owner(s) are credited and that the original publication in this journal is cited, in accordance with accepted academic practice. No use, distribution or reproduction is permitted which does not comply with these terms. 